\title{
Cesarean Section Beyond Cesar's Borders: A Mini Review on the Cultural History of Cesarean Section High Prevalence Rates in the Middle East
}

\author{
Afshin Azimirad, $\mathrm{MD}^{1,2,3^{*}}(\mathbb{D})$ \\ 1Postdoctoral Research Fellow, Obstetrics and Gynecology Department, Tufts Medical Center, Boston, MA, USA \\ ${ }^{2}$ Infertility Research Center, Shiraz University of Medical Sciences, Shiraz, Iran \\ ${ }^{3}$ Student Research Committee, Shiraz University of Medical Sciences, Shiraz, Iran
}

\begin{abstract}
Cesarean section rates have risen significantly in some Middle Eastern countries like Iran, Turkey, and Egypt. Therefore, this review aims to investigate the cultural background for the high cesarean section rates in some Middle Eastern countries to provide the obstetricians and policymakers a better perspective on the crisis. Firstly, the dimensions of the current crisis in the Middle East are discussed. Then, three famous medieval authors are investigated; Ferdowsi (Shahnameh; the birth of Rostam, the Persian superhero, through the cesarean section), Abu Rayhan Biruni (The Remaining Signs of Past Centuries), and Ibn Abi al-Hadid. All these medieval sources try to teach how proud is the one who is born through a cesarean section, and thus a person born vaginally is of a lower rank and therefore less respected. Then, the influencing ancient resources dealing with this subject are reviewed: the birth of Asclepius, the Greek god of medicine, by his father Apollo through a section on the mother's corpse, and Talmud of the Jews. In ancient times, a birth through the cesarean section was a pure birth, or a gift from gods and restricted to divinities. Hoping to gain a new and comprehensive understanding of this current crisis in the Middle East, the World Health Organization (WHO) guidelines on reducing the prevalence of cesarean section are subsequently introduced. The C-section prevalence has increased significantly in the Middle East; comprehensive national, regional, and international policies are highly demanded.

Keywords: Cesarean Section, Iran, Maternal Mortality, Middle East, Obstetric Delivery, Prevalence

Cite this article as: Azimirad A. Cesarean section beyond Cesar's borders: a mini review on the cultural history of cesarean section high prevalence rates in the Middle East. Arch Iran Med. 2020;23(5):335-337. doi: 10.34172/aim.2020.23.
\end{abstract}

Received: November 14, 2019, Accepted: January 26, 2020, ePublished: May 1, 2020

\section{Introduction: A Current Crisis}

The Iranian minister of health once said in a medical seminar in 2015 that the cesarean section prevalence rates have increased from $37 \%$ in 1991 to $52 \%$ in 2013 , and above $90 \%$ in the private centers. He added that Iran has undoubtedly become the pioneer in the region, while the Ministry of Health did not have any plans to control it at some points. ${ }^{1}$

Moreover, two different Iranian systematic reviews and meta-analyses reported the cesarean delivery prevalence rates to be at $48 \%$, and an observational study found out that the C-section rates increased from $14 \%$ in 1979 to $85 \%$ in 2009 in a public Iranian hospital. ${ }^{2-4}$ In Turkey and Egypt, the circumstances are almost the same. One study which collected the nationally-representative data from 150 countries throughout the world from 1990 to 2014 reported that Egypt (51.8\%) has the highest C-section rates in Africa, and Iran (47.9\%) and Turkey (47.5\%) have the highest in Asia. During those 24 years, the global "Average Annual Rate of Increase" for C-section was 4.4\%, while it was respectively $7.9 \%$ and $6.4 \%$ for Northern Africa and Western Asia, ranking them as the second and third in the world. ${ }^{5}$

Since 1985, an "Ideal Rate" for C-section has been defined; 10\%-15\%. In 2015, the World Health Organization (WHO) asserted that a cesarean section is beneficial only when it is medically indicated. Otherwise, rates over $10 \%$ will not improve the maternal and newborn mortality rates. The WHO concluded the C-section should be reserved only for the medical purposes. ${ }^{6}$

There is no doubt that the extremely high rates of C-sections are one of the most important obstetric challenges for some countries in the Middle East. An emergency action is required, because these numbers mean higher maternal mortality rates. Moreover, its rising trend in the recent years clearly alarms us that this situation is more complicated to be solved soon.

An Iranian systematic review and meta-analysis proposed "physician recommendation, fear of NVD pain, attention to infant and mother health, mother's request, mother's higher education, being employed and mother's higher pregnancy age" as the leading factors to opt for a cesarean section. ${ }^{3}$ In 2010, the WHO also asserted that women who are married or educated are more likely to have a 
non-medical cesarean delivery. ${ }^{7}$ An Iranian cross-sectional research, by focusing on the females, concluded that "the higher educational levels of mothers and husbands, mothers' unacceptable level of knowledge regarding complications of C-section, and mothers and husbands positive attitude toward C-section" cause the females to prefer the cesarean to vaginal delivery. ${ }^{8}$

These all together suggest that the problem is not so simple to be confronted without any policy or plan.

In the Middle East, the tendency to have a non-medical cesarean among some women seems to be much more extensive and, indeed, undiscovered - like an iceberg. When a phenomenon with such dimensions appears, seemingly it has roots in the culture of that region. The Middle East, known as the cradle of human civilization, is an old region with the thousands of years of history and culture, also the birthplace of the major religions of the world. Thus, people who live in the area inherit a boundless legacy of thousands of years. To make comprehensive policies for this crisis, paying attention to its position in history and culture will be definitely beneficial. This narrative mini-review has taken a new look at the books from the three medieval authors (Ferdowsi, Biruni and Ibn Abi al-Hadid), the ancient sources on Asclepius, the Greek god of medicine, and the Babylonian Talmud, an ancient book, to perceive the attitude of the medieval and ancient people of the region toward the cesarean section, as the cultural roots of the current crisis.

\section{A Medieval Pride}

Ferdowsi

Ferdowsi (10th and 11th centuries) is one of the four major Persian poets of all time and one of the greatest epic poets in the history of literature. He is the author of the Shahnameh (Book of Kings), the national epic of Persia. Rostam, a national legendary superhero in Iran, is the main protagonist of his book. Comparable to Hercules, however, more bound to the Persian people. Rostam's mother is Rudabeh, the princess of Kabul, which those days was part of Iran. Rudabeh delivers Rostam by a cesarean section. Ferdowsi has written a detailed explanation on her cesarean delivery (to the most popular Iranian hero), however, in a poetic language. Briefly, as Rudabeh's delivery becomes complicated, Zal, her husband, calls Simorgh, the legendary divine bird in the Iranian mythology. Simorgh, who makes prophecies and acts as a parent and moral teacher from heavens, first reassures $\mathrm{Zal}$ that a good fate is promised for this birth, and then teaches Zal how to perform a section. Simorgh wants him to bring a knife as lucid as water and take the wise man who knows the secrets out of himself by calming his anxiety, (a poetic expression; to calm himself). Then, Simorgh wants him to give her so much wine to make her drunk, then incise her pubis when she cannot perceive pain. Afterwards, he should take the baby lion (Rostam, the legendary hero) out, while Rudabeh's flank is all in blood. Then, he should suture her incision, and make a salve from a ground-dried mixture of a special herb, milk, and musk. The salve will immediately heal the wound of the section. Subsequently, he should put a Simorgh's feather on the section since that is sacred, and then pray to God. Simorgh's last teaching to $\mathrm{Zal}$ is that he should never feel sorrowful for any of these, since this is the moment that the tree has given blossom.

Biruni

Abu Rayhan Al-Biruni is probably the greatest Iranian scientist of all time, second only to Avicenna. He was a contemporary of Ferdowsi and, like him, fond of myths, legends, and culture. However, among many fields he mastered, (he was a prolific astronomer, physicist, mathematician, geographer, historian, anthropologist, linguist, Indologist, and Iranologist), he never wrote poems. In one of his famous books, The Remaining Signs of Past Centuries, Biruni refers shortly to a man who was born through a cesarean section and depicts the atmosphere around him. The man was Ahmad ibn Sahl ibn Yazdgerd, a general, a feudal and a well-known prince in the 10th century Transoxiana. The book is written in Arabic.

Biruni has written, "Caesar's mother died antepartum, so her abdomen was incised, and Caesar was taken out. Thus, Caesar always felt proud, since he was not born out of a vagina, therefore used to boast about that to the other kings. Ahmad ibn Sahl used to be proud of the same matter too, like Caesar. Whenever he wanted to curse other people, he used to call them, 'O, son of a vagina!'”

\section{Ibn Abi al-Hadid}

Ibn Abi al-Hadid was a Muslim theologian of the 13th century in the Mesopotamia, an eyewitness of the Mongol invasions. His most famous book, which is named after himself, is a religious commentary in Arabic. In its seventh volume, he asserts, "Angels are more honorable than humans for four reasons". His second reason is "they do not reside in the uterus (through their life cycle). And there is no doubt that anyone who does not come out of that filthy place is more honorable than who does!" Then, in the following, he quotes Biruni and his same story and explanations on Caeser and Ibn Sahl.

\section{A Life-Saving Miracle in the Ancient Middle East}

In ancient times, the western half of the Asia Minor was inhabited by the Greeks. However, after Alexander, the Greeks ruled over the Middle East for some centuries. Asclepius, their god of medicine, was a son to Apollo; a god, and Coronis; a non-god. The mortal woman died, and Apollo performed a section on her corpse to save the neonate-god!

Talmud, the main repository of the oral Torah of the Jews, was written in the 3 rd to 5 th centuries; however, it is 
conventionally believed to be containing the same ancient teachings of Moses. It was written in Babylonia, which was meanwhile the capital of the Iranian Parthian and Sasanian empires. Talmud extensively discusses C-section to clarify the Jewish rites and laws associated with it. For example, in the seventh tractate (Keritot) of Seder Kodashim, there is a part about the religious offerings after a birth. There, it is said, "The following bring no offering at all: the woman who discharges a fetus filled with water or with blood or with a many-colored substance; or if the abortion was in the shape of fish, locust, unclean animals or reptiles; or if the miscarriage took place on the fortieth day (after the conception); or if it was extracted by means of a caesarean section. Rabbi Simeon declares her liable (to an offering) in the case of a caesarean section".?

Boss has assessed C-section in the ancient Jewish books in detail. He believed that cesarean used to be practiced widely in ancient times in that region, and mostly for two indications: 1) to deliver a neonate from a corpse to save his/her life, 2) to deliver a neonate from a mother to save both mother and child. Boss also concluded that the operation was probably learned in the times of the Babylonian Exile or developed in the Persian times to save lives. ${ }^{10}$

\section{Conclusion}

Now that the roots and cultural background of the cesarean section have been shortly previewed, it is time to get back to the "now"! Indeed, there is a crisis going on currently: the prevalence of C-sections is extremely high in some Middle Eastern countries, there is no solid policy for that, and most dangerous of all, $\mathrm{C}$-sections are becoming more acceptable every day.

In 2018, the WHO called the rise in non-necessary sections a universal problem. To help the policymakers, the WHO recommendations "are grouped according to the target of intervention: A) Interventions targeted at women; B) Interventions targeted at health-care professionals; and C) Interventions targeted at health organizations, facilities or systems."

The policies the WHO recommends for group A are: "Childbirth training workshops, nurse-led applied relaxation training program, psychosocial couple-based prevention program, and psychoeducation for women with fear of childbirth." For group B: "Implementation of evidence-based clinical practice guidelines combined with structured, mandatory second opinion for caesarean section indication." And for group C: "Collaborative midwiferyobstetrician model of care (i.e. a model of staffing based on care provided primarily by midwives, with 24 -hour backup from an obstetrician who provides in-house labor and delivery coverage without other competing clinical duties), and financial strategies (i.e. insurance reforms equalizing physician fees for vaginal births and caesarean sections) for health-care professionals or health-care organizations". ${ }^{11}$

In the end, the Cesarean section rates have increased significantly in the Middle East, and accordingly, comprehensive national, regional, and international policies are highly demanded.

\section{Conflict of Interest Disclosures}

None.

\section{Ethical Statement}

Not applicable.

\section{Acknowledgments}

The contributions of Infertility Research Center, Obstetrics \& Gynecology Department, and Student Research Committee are highly acknowledged.

\section{References}

1. Iranian Ministry of Health. Madaran bayad ba mazayaye zayeman e tabiee ashena shavand. Available from: https:// web.archive.org/web/20150729155701/http://behdasht.gov. ir/?siteid=1 \&pageid=1508\&newsview=129454. Accessed April 13, 2020.

2. Azami-Aghdash S, Ghojazadeh M, Dehdilani N, Mohammadi $M$. Prevalence and causes of cesarean section in Iran: systematic review and meta-analysis. Iran J Public Health. 2014;43(5):545-55.

3. Rafiei M, Ghare MS, Akbari M, Kiani F, Sayehmiri F, Sayehmiri K, Vafaee R. Prevalence, causes, and complications of cesarean delivery in Iran: A systematic review and meta-analysis. Int J Reprod Biomed (Yazd). 2018;16(4):221-34.

4. Badakhsh $\mathrm{MH}$, Seifoddin M. Rise in cesarean section rate over a 30-year period in a public hospital in Tehran, Iran. Arch Iran Med. 2012;15(1):4-7.

5. Betrán AP, Ye J, Moller AB, Zhang J, Gülmezoglu AM, Torloni $M R$. The increasing trend in caesarean section rates: global, regional and national estimates: 1990-2014. PLoS One. 2016;11(2):e0148343. doi: 10.1371/journal.pone.0148343.

6. World Health Organization. WHO statement on caesarean section rates. World Health Organization; 2015. Available from: http://www.who.int/iris/handle/10665/161442.

7. World Health Organization. Caesarean section without medical indication increases risk of short-term adverse outcomes for mothers: policy brief. Geneva: World Health Organization; 2010. Available from: http://www.who.int/iris/ handle/10665/70494.

8. Maharlouei N, Rezaianzadeh A, Hesami E, Moradi F, Mazloomi E, Joulaei $\mathrm{H}$, et al. The preference of Iranian women to have normal vaginal or cesarean deliveries. J Res Med Sci. 2013;18(11):943-50.

9. Babylonian Talmud, Seder Kodashim, Tractate Keritot, 7b. Available from: https://halakhah.com/pdf/kodoshim/Krithoth. pdf. Accessed April 4, 2019.

10. Boss J. The antiquity of caesarean section with maternal survival: the Jewish tradition. Med Hist. 1961;5(2):117-31. doi: $\quad 10.1017 / \mathrm{s} 0025727300026089$

11. World Health Organization. WHO recommendations nonclinical interventions to reduce unnecessary caesarean sections. World Health Organization; 2018. Available from: http://www.who.int/iris/handle/10665/275377. 